\title{
Suitability of DIC and ESPI optical methods for monitoring fatigue damage development in $\mathrm{X} 10 \mathrm{CrMoVNb9-1}$ power engineering steel
}

\author{
M. Kopec ${ }^{1,2}$ (1) A. Brodecki ${ }^{1} \cdot$ D. Kukla ${ }^{1} \cdot$ Z. L. Kowalewski ${ }^{1}$
}

Received: 20 July 2021 / Revised: 14 September 2021 / Accepted: 3 October 2021 / Published online: 12 October 2021

(c) The Author(s) 2021

\begin{abstract}
The aim of this research was to compare the effectiveness of two different optical measurement techniques (digital image correlation-DIC and electronic speckle pattern interferometry-ESPI) during fatigue damage development monitoring in $\mathrm{X} 10 \mathrm{CrMoVNb} 9-1$ (P91) power engineering steel for pipes. The specimens machined from the as-received pipe were subjected to fatigue loadings and monitored simultaneously using DIC and ESPI techniques. It was found that DIC technique, although characterised by lower resolution, was more effective than ESPI. DIC allows to monitor the fatigue behaviour of steel specimens and accurately indicate the area of potential failure even within the initial stage of fatigue damage development.
\end{abstract}

Keywords Fatigue development · Damage · P91 steel · Digital image correlation (DIC) · Electronic speckle pattern interferometry (ESPI)

\section{Introduction}

Material behaviour under various loading types could be successfully determined by using different measurement techniques. The most conventional method includes extensometer recordings during both, static and fatigue tests for subsequent strain component measurements. Such methodology enables continuous recording of strain changes in a particular direction defined at the beginning of mechanical test. Moreover, the extensometers can only monitor a displacement on the limited strain gauge, and more importantly, give only an average values of it. This is a serious limitation of the technique, particularly in the case of fatigue investigations. Although fatigue phenomenon has been investigated by many research centres for more than two ages, there are still a lot of difficulties in the prediction of crack initiation under cyclic loading, especially under multiaxial stress conditions. It is well known that the process of fatigue damage development and structural degradation is of local nature,

M. Kopec

mkopec@ippt.pan.pl

1 Institute of Fundamental Technological Research Polish Academy of Sciences, 5b Pawińskiego Str, 02-106 Warsaw, Poland

2 Department of Mechanical Engineering, Imperial College London, London, UK, SW7 2AZ and as a consequence, an application of the above-mentioned conventional extensometers for strain measurements cannot reflect strain distribution along the gauge length of the specimen tested, Fig. 1. As illustrated schematically in Fig. 1, the indication of the crack initiation location within the gauge length is practically impossible using the conventional extensometers. Such a problem may be effectively solved by the application of DIC or ESPI full-field optical methods.

DIC is a stereoscopic technique in which two CCD cameras, light sources and computational software are used. A mathematical theory of DIC was presented by Chu et al. [1]. In this method, a specimen needs to be covered with a special pattern (black dots on a bright background) [1, 2]. Such pattern defines the $x$ and $z$ coordinates which are further used to run the test under strain control. The origins of rectangular- or square-shaped pattern are directly applied to calculate the displacement/strain. The results obtained are presented in the form of full-field strain distribution maps [2]. The DIC method is mainly used for static measurements in which tensile and compressive behaviour [3], fracture toughness [4] and the geometrical imperfection effects on mechanical response [2] are investigated in detail.

ESPI is the holographic interferometry-type technique based on the laser beam analysis distracted from the optically rough surface. The specimen surface is captured as an image by the CCD (charge-coupled device) sensor and transferred to a working station. As the first beam illuminates the 


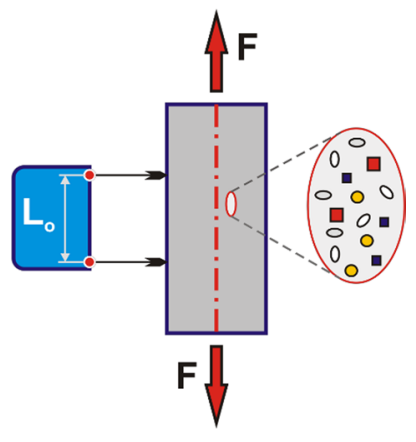

Fig. 1 Standard technique of strain measurements during fatigue

specimen surface, the reflected beam interferes with the reference beam, and thus the subtraction process of the speckle interferograms (before and after loading up to the defined levels) is performed and correlation fringes are obtained. The fringes enable generating a phase map with distribution of displacement components in each direction separately [5]. Subsequent mathematical operations under the fixed boundary conditions (measurement area dimensions) and the material parameters (Young's modulus and Poisson's ratio) led to the final full-field stress and strain phase maps. ESPI, although different in terms of operation principles, is quite similar to DIC optical technique, for which also the displacement maps during loading can be obtained. It should be mentioned however, that it has significantly higher than DIC resolution. More importantly, it is mainly laboratory scale dedicated due to a high vibration sensitivity, which disturbs seriously the results captured.

Both ESPI and DIC have many applications. DIC was used to study different kinds of materials, such as soft and hard biological tissues [6-9], dental materials [10], hightemperature applications [11], structural dynamics [12], residual stress and its error estimation [13], in situ monitoring of additive manufacturing [14], and many others. On the other hand, ESPI has been recently employed for assessing the integrity of structural materials, evaluating residual stress fields in pipes, measuring surface displacements during inflation testing of ocular tissues or assessing strain in bone-implant interfaces [15].

The application of both these methods during testing enables to locate the stress concentration area and further predict the potential region where fracture could occur. They were previously used to monitor strain distribution of a biaxially loaded cruciform specimens. It was reported that both ESPI and DIC gave similar results, but ESPI could only be applied in uniaxial test cases due to its incapability to cope with the vibrations of the biaxial testing bench [16]. Optical techniques were also used for full-field stress measurement for in situ structural health monitoring of airframe components [17]. Siebert et al. [18] presented recent developments and applications for optical full-field strain measurement using ESPI and DIC. In this research, the ESPI technique was applied for determination of strain under static loading in composite and inhomogeneous materials and was applied for optimisation of the design of components in automotive applications. On the other hand, DIC was found to be extremely useful for full-field three-dimensional displacement and strain measurements in real time, which enabled in situ monitoring of the test itself. Bingleman et al. [19] used DIC to track speckle motion caused by specimen displacement between ESPI measurements. The images measured by DIC were mathematically shifted to restore the original speckle locations to further eliminate the vibration-caused noise during the ESPI measurements. It was found that application of correcting asymmetries or parallel illumination beams could successfully eliminate such measuring issue. ESPI was successfully used to detect the crack initiation in coatings and the delamination occurrence at the coating/substrate interface during the fatigue $[20,21]$. It should be mentioned, however, that the differences between hard coating and substrate material enable to localise the stress concentrators (hard phases or particles) much easier, than on homogenous material; therefore, the ESPI measurements are relatively easy to perform. Additionally, geometrical features, like holes or notches, could be used as stress and strain concentration inducers [22]. Their presence during fatigue testing enables to monitor strain distribution and analyse damage growth in the microstrain regime. It is also known that in cyclic loading, heterogeneous deformation is mainly determined by the structural integrity of components, and therefore, the fatigue crack initiation is driven by the micromechanical response during cyclic loading and subsequent microstructural changes including persistent slip bands and cyclic twins that could further lead to crack nucleation and initiation [23, 24]. However, the high sensitivity to vibration of ESPI setup practically narrows its application to the laboratory scale. On the other hand, the DIC was successfully used to determine the fatigue life of different materials, for example: aluminium alloys [25], nickel-based alloys [26], glass fibre-reinforced polymer composites [27], woven organic matrix composites [28] or even asphalt concrete [29].

Despite many applications of both optical techniques, one can indicate that the comparison of DIC and ESPI optical measurement effectiveness for fatigue damage development monitoring has not been investigated in detail as yet. Therefore, the main aim of this work was to perform a series of fatigue tests on specimens with the same geometry and assess the effectiveness of both techniques during measurements carried out under the same conditions. 
Table 1 Chemical composition of the as-received P91steel (data captured from tests compared to that required according to the Polish Standards PN 10216-2:2004 [30])

\begin{tabular}{lllllllllll}
\hline & $\mathrm{C}$ & $\mathrm{Mn}$ & $\mathrm{Cr}$ & $\mathrm{Mo}$ & $\mathrm{V}$ & $\mathrm{Ni}$ & $\mathrm{Cu}$ & $\mathrm{Si}$ & $\mathrm{S}$ & $\mathrm{P}$ \\
\hline $\begin{array}{l}\text { As-received state } \\
\begin{array}{l}\text { Required according to } \\
\text { PN 10216-2:2004 }\end{array}\end{array}$ & 0.12 & $0.08-0.12$ & $0.3-0.6$ & $8-9.5$ & $0.85-1.1$ & $0.18-0.25$ & $<0.4$ & $<0.3$ & $0.2-0.5$ & $<0.01$ \\
\hline
\end{tabular}

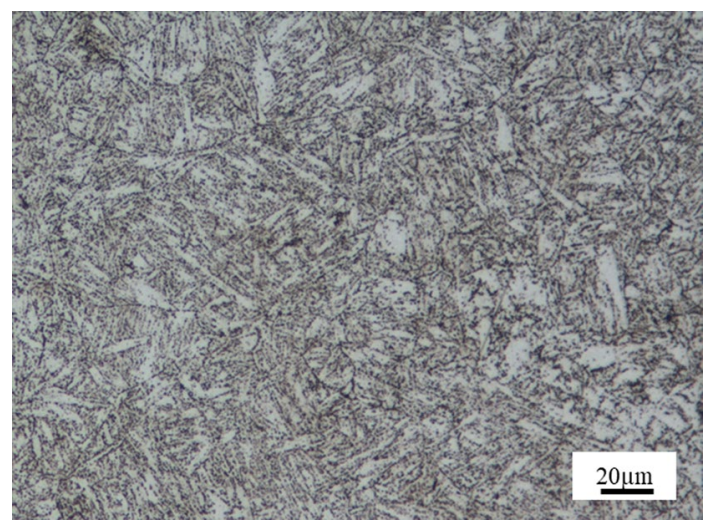

Fig.2 The microstructure of P91 steel in the as-received state

\section{Materials and methods}

\subsection{Characterisation of material}

Fatigue testing was performed on wire-cut specimens made of P91 heat-resistant steel in the as-received state (normalising at $1050{ }^{\circ} \mathrm{C}$ for $2 \mathrm{~h} /$ oil cooling, tempering at $750{ }^{\circ} \mathrm{C} / 2 \mathrm{~h}$ /air cooling). Prior to the testing, the material was subjected to chemical composition analysis (EDS) to confirm the agreement with the Polish Standards (PN 10216-2:2004) [30], as presented in Table 1. The content of alloying elements remained at acceptable level in comparison to the standard range. The microstructure of P91 steel is presented in Fig. 2 where the needle-shaped tempered martensite forming zigzag groups with carbide secretions can be observed. This is typical microstructure of P91 steel after normalisation and tempering as reported in $[31,32]$. The chemical composition analysis was performed using scanning electron microscope J0L6360 LA, while the microstructures were observed using light microscope (OLYMPUS PMG3).

The engineering drawing of specimen designed for fatigue tests is shown in Fig. 3.

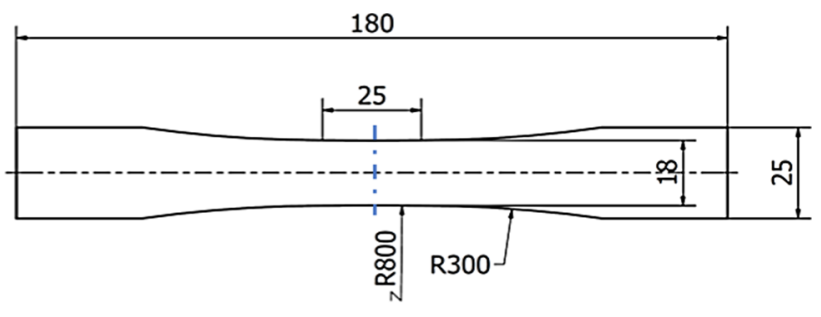

\section{윤=}

Fig. 3 The geometry of the specimen (in $\mathrm{mm}$ )

\subsection{Experimental details}

Before an execution of the main experimental programme, the preliminary tests were carried out. They included standard tensile tests to determine the basic mechanical parameters that were subsequently used to define fatigue loading conditions. All tensile tests were performed at the strain rate equal to $2 \times 10^{-4} \mathrm{~s}^{-1}$.

Standard fatigue tests and uniaxial tensile tests were performed on the MTS 858 testing machine, with an axial force range of $\pm 25 \mathrm{kN}$ and a torque of $\pm 200 \mathrm{Nm}$, controlled by a TestStar II using such software as TestWare-SX v. 4.0D and 790.20 Fatigue Test Application.

The fatigue tests were force controlled with zero mean level and a constant stress amplitude with a frequency of $20 \mathrm{~Hz}$ in the range of stress amplitude from $\pm 400 \mathrm{MPa}$ to $\pm 640 \mathrm{MPa}$. The range of fatigue loads was established on the basis of the yield strength $\mathrm{R}_{0.2}$ determined from the uniaxial tensile test. The fatigue development was monitored by Dantec Dynamics Q100 ESPI system and DIC Aramis $12 \mathrm{M}$ equipped with lenses of total focal length of $75 \mathrm{~mm}$ and calibration settings appropriate to the measuring area equal to $170 \times 156 \mathrm{~mm}$. The calibration was performed prior to testing using a certified GOM calibration plate. The general view of the experimental setups are presented in Fig. 4. The loading programmes in experiments supported by ESPI system and DIC system are presented in Fig. 5. During the ESPI measurement, the first cycle conducted manually was followed by a block of cycles under the frequency of $20 \mathrm{~Hz}$ performed by the testing machine. The process of cyclic loading was interrupted several times to perform displacement measurements using the ESPI camera. On the other 

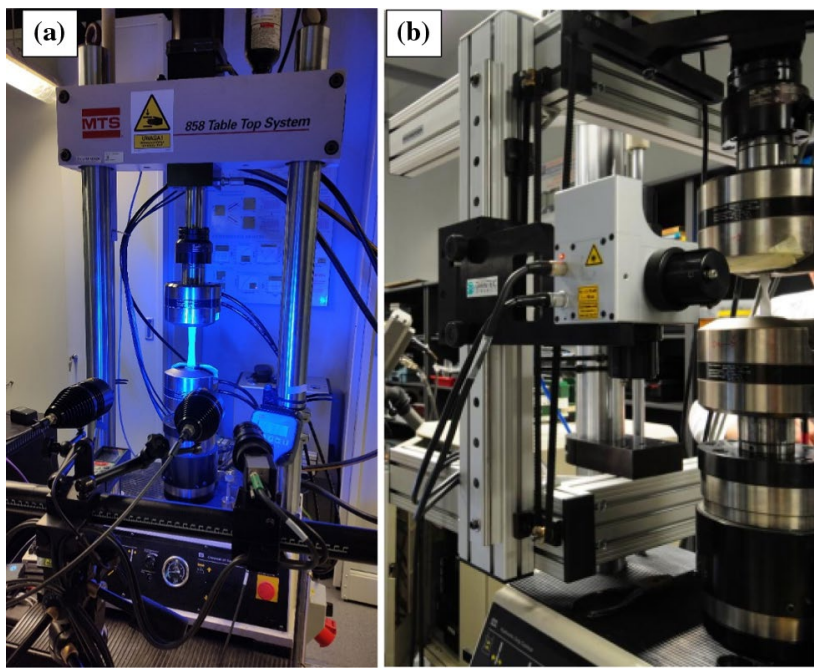

Fig. 4 General view of the experimental setup: DIC (a); ESPI (b)

hand, Aramis software enabled to capture DIC images automatically at a frequency corresponding to 1000 fatigue cycles. The experimental programme for both methods provided displacement measurements at the beginning of the test and after a specific number of cycles. The suitability of the ESPI method for fatigue monitoring was assessed for stress amplitudes of $500 \mathrm{MPa}, 550 \mathrm{MPa}, 600 \mathrm{MPa}$ and
Table 2 Mechanical parameters of P91 steel obtained in experiment and according to the Polish Standards PN10216-2: 2004 [30]

\begin{tabular}{lllll}
\hline & $\mathrm{R}_{\mathrm{m}}[\mathrm{MPa}]$ & $\mathrm{R}_{0.2}[\mathrm{MPa}]$ & $\mathrm{A}[\%]$ & $\mathrm{E}(\mathrm{GPa})$ \\
\hline As-received state & $900( \pm 16)$ & $661( \pm 9)$ & $23( \pm 1)$ & $210( \pm 5)$ \\
PN: 10216-2:2004 & $630-830$ & $>450$ & $17-19$ & - \\
\hline
\end{tabular}

$630 \mathrm{MPa}$, while for DIC their values were equal to $500 \mathrm{MPa}$, $600 \mathrm{MPa}, 630 \mathrm{MPa}$ and $640 \mathrm{MPa}$.

\section{Results}

\subsection{Preliminary tests for mechanical parameter identification of P91 steel}

The selected mechanical properties of P91 steel were determined on the basis of static tensile tests. To obtain reliable results of the tensile tests, five specimens were tested accordingly (Fig. 6a). The average values of parameters determined from these tests are presented in Table 2. All of them are close to those suggested by the PN10216-2: 2004 standards [30]. The higher values of $R_{m}$ and A result from heat treatment of the as-received material. It was reported in [31, 32] that a normalising temperature of $1050{ }^{\circ} \mathrm{C}$ and a tempering
Fig. 5 Loading programme in experiments supported by: ESPI system (a); DIC system (b) (a)

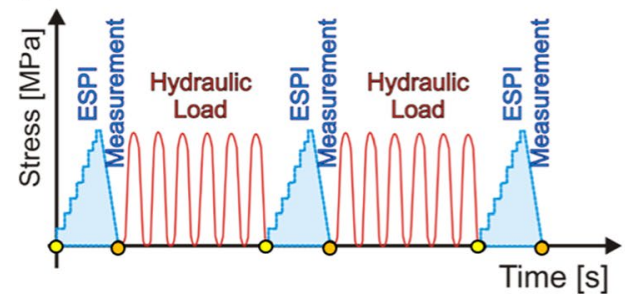

(b)

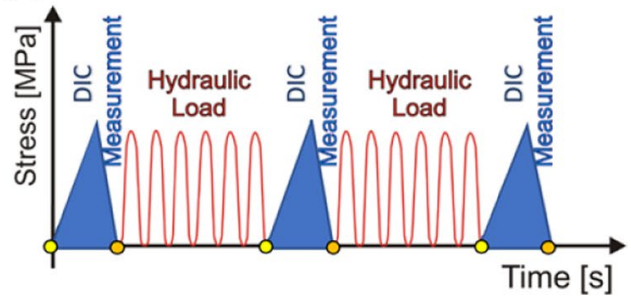

(a)

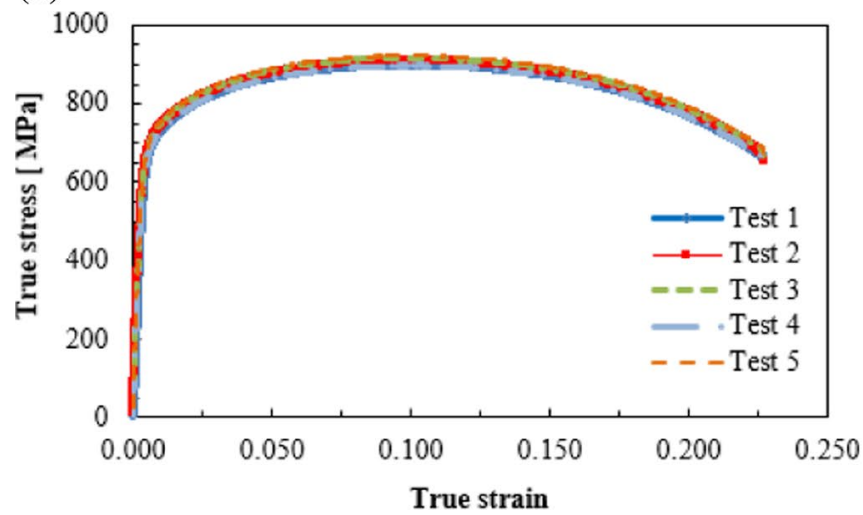

(b)

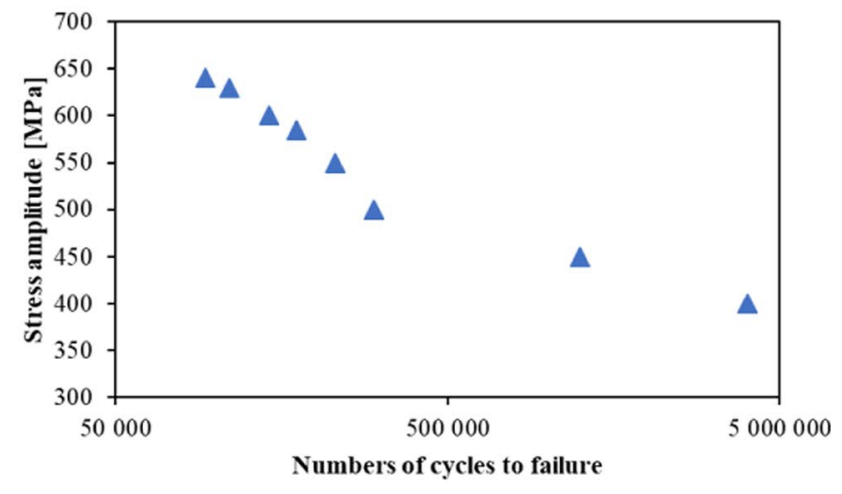

Fig. 6 Strain-stress (a) and S-N curves (b) for the steel in the as-received state 
temperature of $760{ }^{\circ} \mathrm{C}$ provide the best combination of strength, ductility and microstructure. In the next step of the experimental programme, fatigue tests with different values of stress amplitude were carried out. Figure 6 illustrates the $\mathrm{S}-\mathrm{N}$ curve that summarises the fatigue results obtained. The fatigue damage development was monitored using both ESPI and DIC techniques.

\subsection{ESPI measurements}

The exemplary ESPI measurements for the stress amplitude equal to $500 \mathrm{MPa}$ after selected number of cycles up to the specimen fracture are presented in Fig. 7. The specific areas of higher strain accumulation are presented in the strain distribution maps in dark red. An area of the relatively (a)

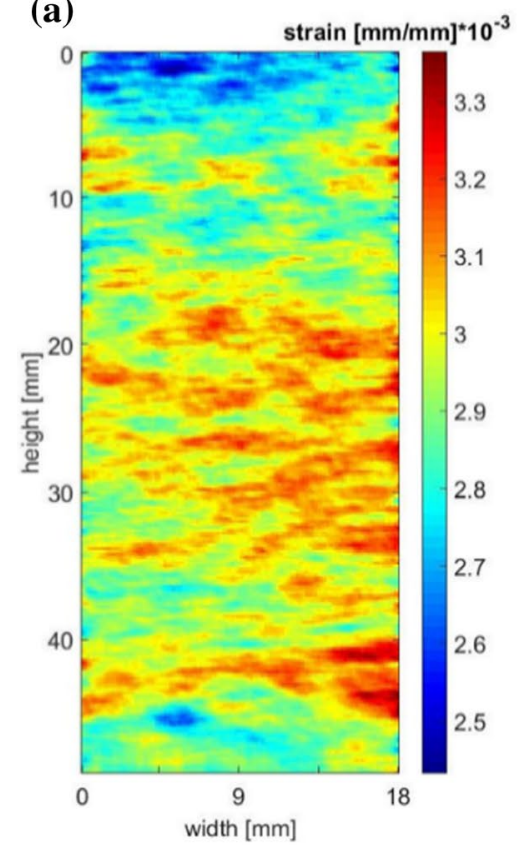

(b)

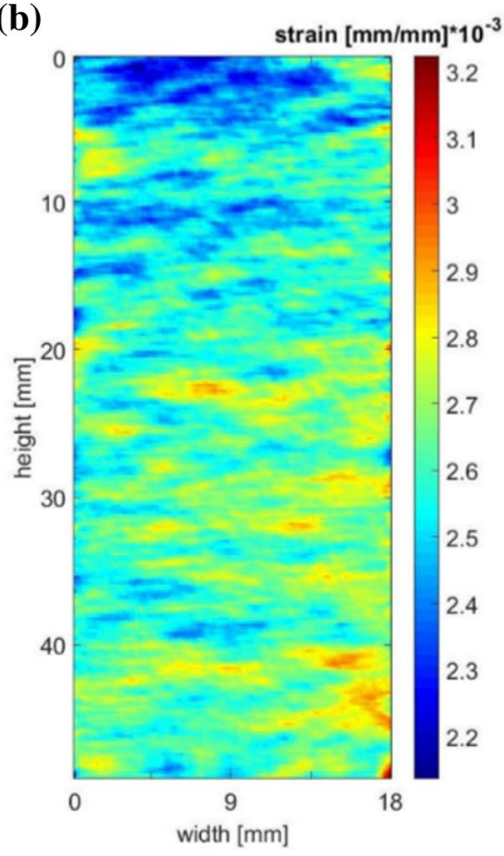

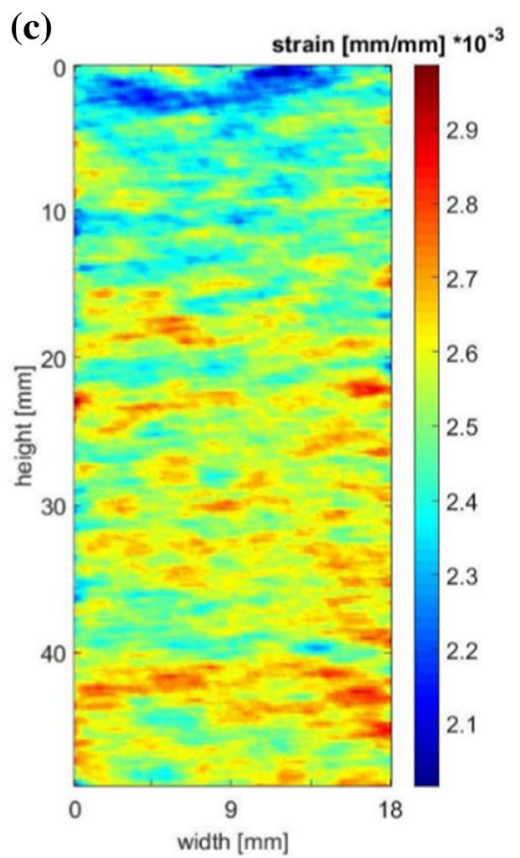
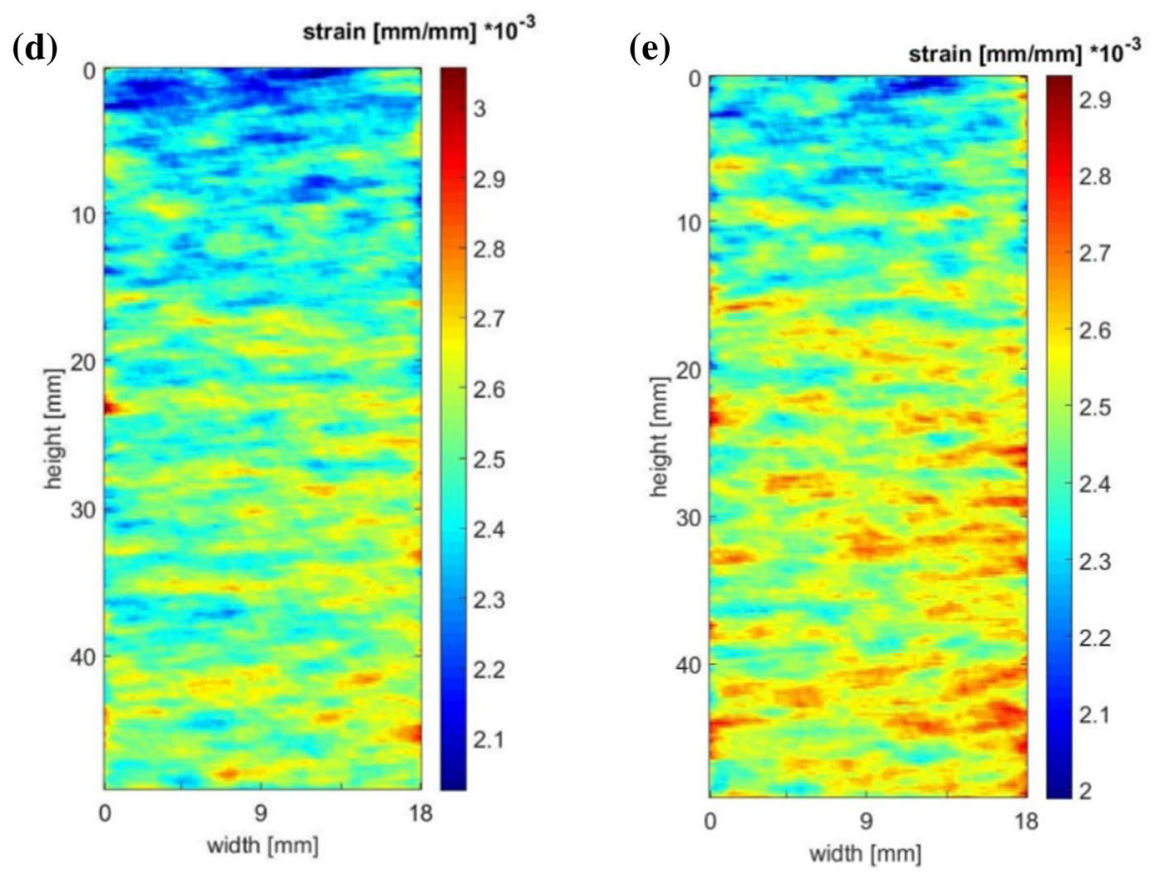

Fig. 7 ESPI measurements performed for the stress amplitude equal to $500 \mathrm{MPa}$ with variable scale after: 1 cycle (a); 1000 cycles (b); 10,000 (c); 100,000 cycles $(\mathbf{d}) ; 225,000$ cycles $(\mathbf{e})$ 
high accumulation of strain was found after the first cycle (Fig. 7a), indicating that the specimen was subjected to load after clamping it in the testing machine grips. However, after 1000 cycles (Fig. 7b), the strain distribution on the specimen surface stabilises, presumably due to stabilisation of the specimen in testing grips. The fatigue damage development in further cycles (Fig. 7c-e) led to the intensification of strain accumulation at the bottom part of the specimen. The potential areas of crack initiation were found after 225,000 cycles in the lower part of the specimen. However, the measurement made before the fracture (Fig. 8d) indicated a different area of crack than that assumed in the previous measurement. Furthermore, a different scale of strain was applied to clearly present a fracture location on the specimen. On the other hand, the unification of strain scale from 0 to $14 \times 10^{-3}$ unabled to observe any strain distribution (Fig. 8) even after 225,000 cycles.

To eliminate the potential measuring error, additional measurements were performed at the same conditions (Fig. 9). After 100,000 cycles (Fig. 9a), the strain accumulated at the specimen right bottom area. The development of fatigue damage and simultaneous increase of strain values in this area after 250,000 cycles (Fig. 9b) indicated that the fracture should occur in this particular region. However, the crack initiation was localised in the middle section of the measured gauge and was not able to be detected before the specimen fracture (Fig. 9c, f). Again, no strain distribution was observed on the unification of the strain scale (Fig. 9d,e). Each specimen fractured within 1000 cycles from the crack initiation. It should be highlighted that the ESPI measurements were also performed for the stress amplitudes equal to $550 \mathrm{MPa}, 600 \mathrm{MPa}$ and $630 \mathrm{MPa}$; however, the same difficulties for optical crack detection were met. Therefore, strain maps for $500 \mathrm{MPa}$ were presented only.

\subsection{DIC measurements}

To check the applicability of the DIC methodology, measurements were performed for the same stress amplitude as that for the ESPI used, i.e. $500 \mathrm{MPa}$ after a selected number of cycles to the specimen fracture. Unlike the ESPI measurements, the DIC technique captured a strain localisation area after just one cycle (Fig. 10a). The subsequent evolution of fatigue damage to 100,000 cycles enabled to clearly indicate the area of potential crack initiation (Fig. 10b) and its development (Fig. 10c, d) up to specimen fracture.

The effectiveness of the DIC method was further confirmed by performing an additional measurement for the stress amplitude equal to $600 \mathrm{MPa}, 630 \mathrm{MPa}$ and $640 \mathrm{MPa}$ (Fig. 11, 12, 13). For each measurement, the area of potential crack initiation was precisely captured after the initial number of fatigue cycles and the specimens fractured exactly in this specified region. It should be mentioned, however, that the highest values of stress amplitude were required to be applied to modify the scale to clearly present the strain distribution.

\section{Discussion}

Electronic speckle pattern interferometry and digital image correlation are widely used contactless methods for optical strain measurements with a wide range of possible (a)

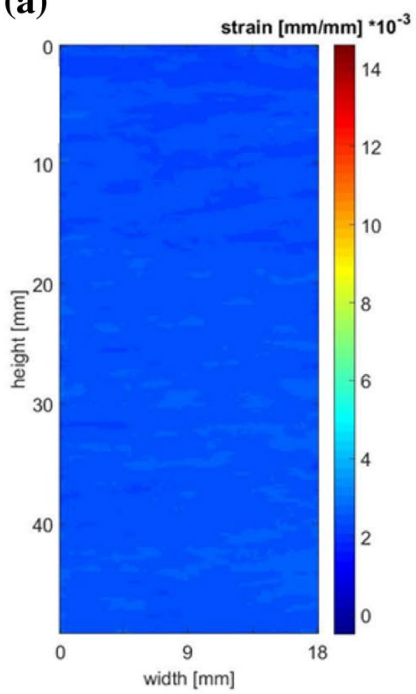

(b)

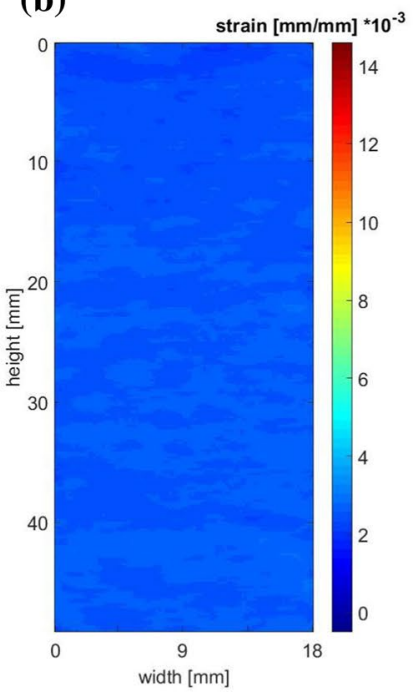

(c)

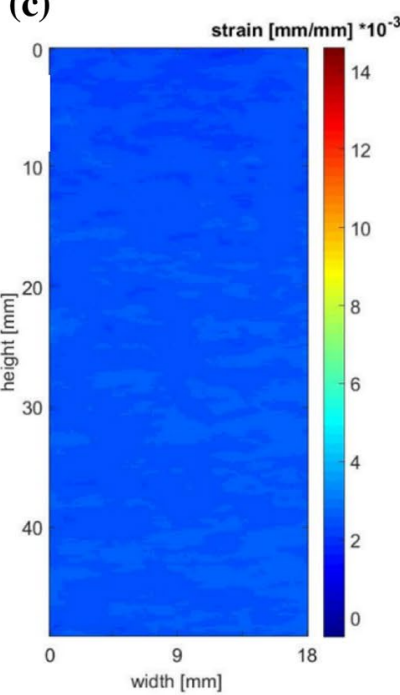

(d)

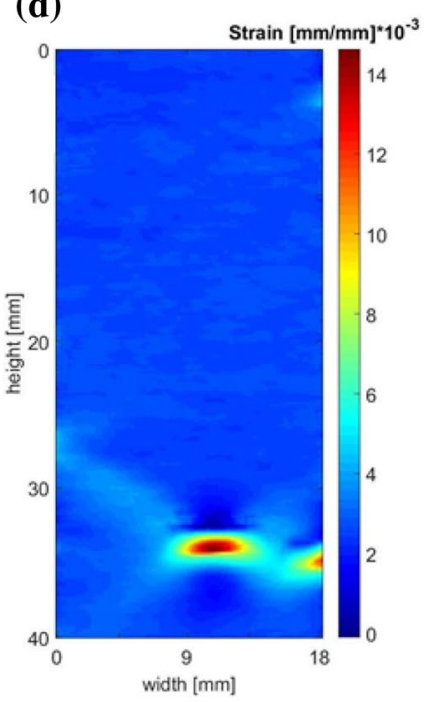

Fig. 8 ESPI measurements performed for the stress amplitude equal to $500 \mathrm{MPa}$ with the unified scale after: 1 cycle (a); 100,000 cycles (b); 225,000 cycles $(\mathbf{c}) ; 245,737$ cycles $(\mathbf{d})$ 

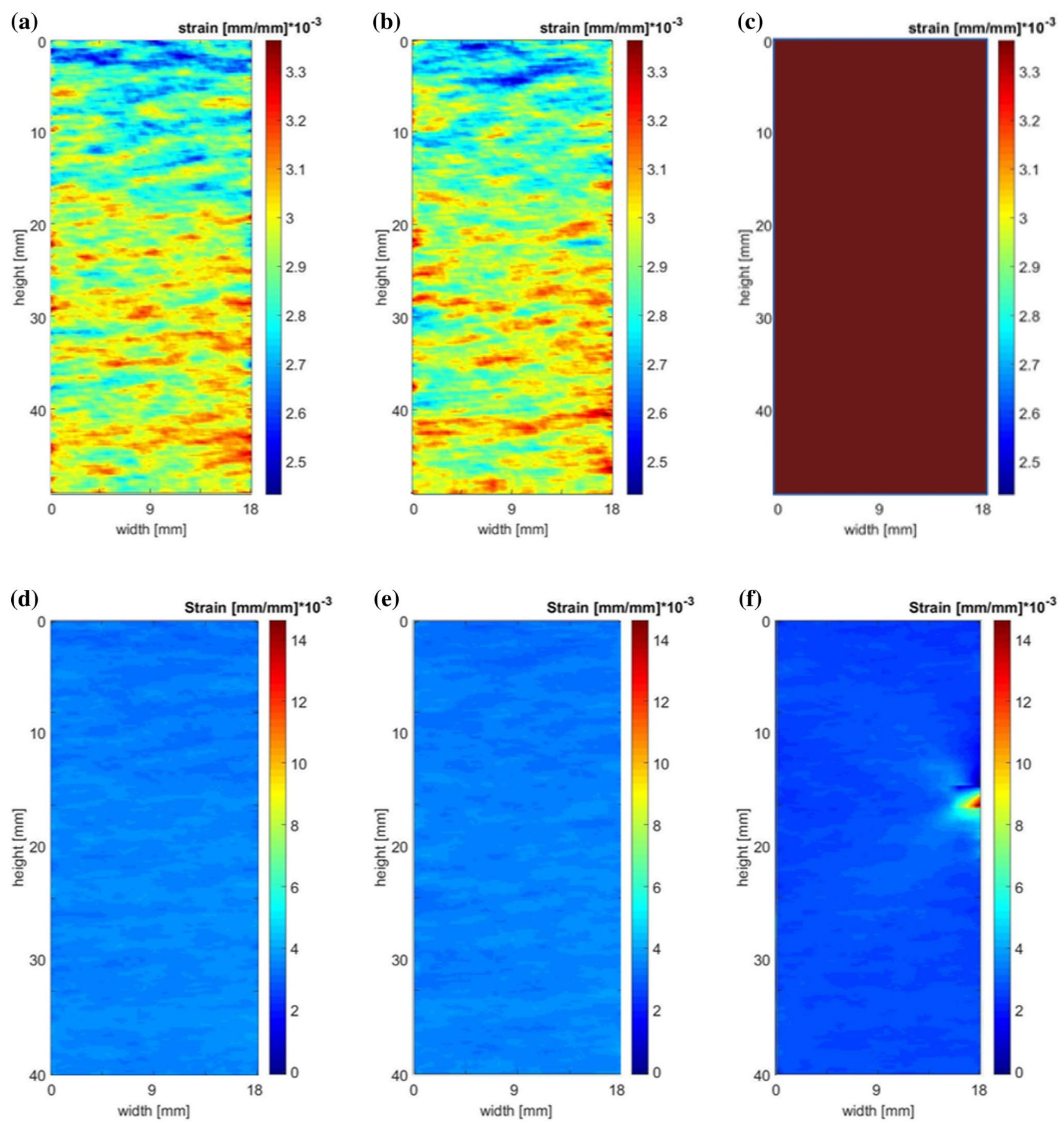

Fig. 9 Comparison of ESPI measurements performed for the stress amplitude equal to $500 \mathrm{MPa}$ with variable scale after: 100,000 cycles (a); 250,000 cycles (b); 299,207 cycles (c); and unified scale after: 100,000 cycles (d); 250,000 cycles (e); 299,207 cycles (f)

applications [33-40]. Their advantages and limitations are presented in Table 3. Both the optical techniques in question enable to overcome several problems that conventional contact sensors (extensometers, strain gauges, etc.) do not. Among them, one can indicate slippage, difficulty in attachment, possibility of the specimen damaging the sensor due to fracture, not being applicable to special materials and small specimens, easily exceeding the range, not working in hostile environment, need of more strain gauges for different directions, and need of different instruments for different parameters [37]. Hence, the effectiveness of these techniques was investigated in detail by many researchers. Bingleman et al. [19] found that a combination of the ESPI and DIC techniques leads 


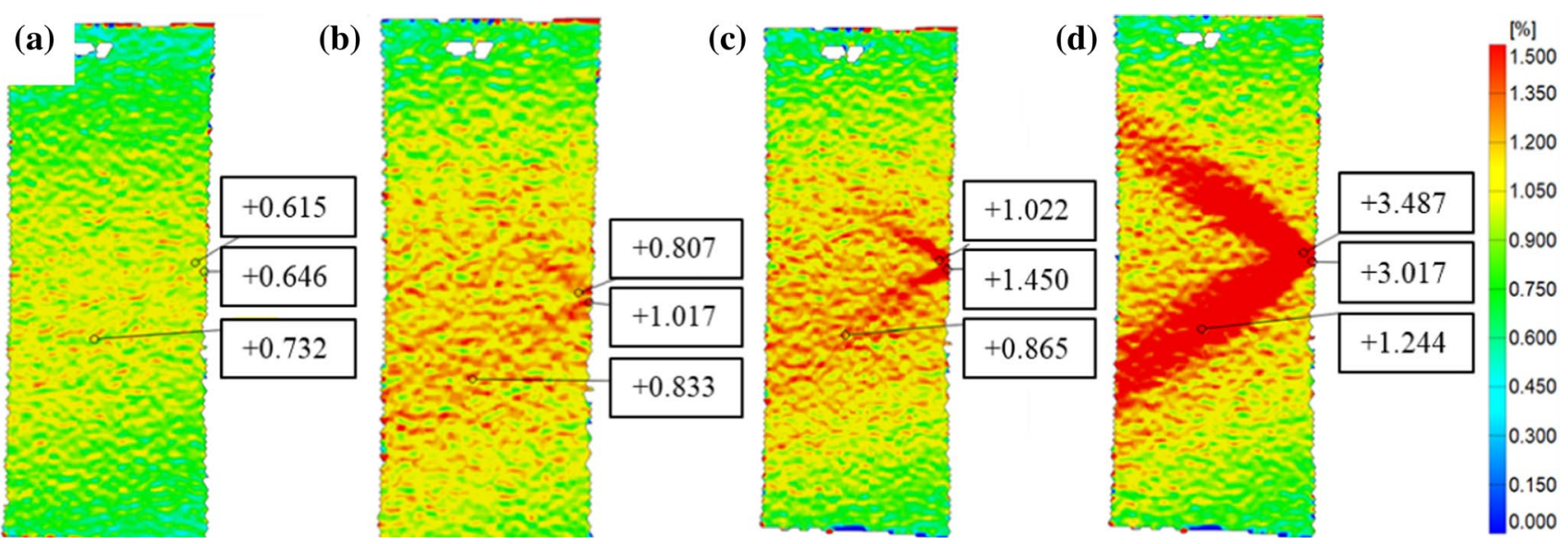

Fig.10 DIC measurements performed for the stress amplitude equal to $500 \mathrm{MPa}$ with unified scale after: 1 cycle (a); 100,000 cycles (b); 250,000 cycles $(\mathbf{c}) ; 301,251$ cycles $(\mathbf{d})$
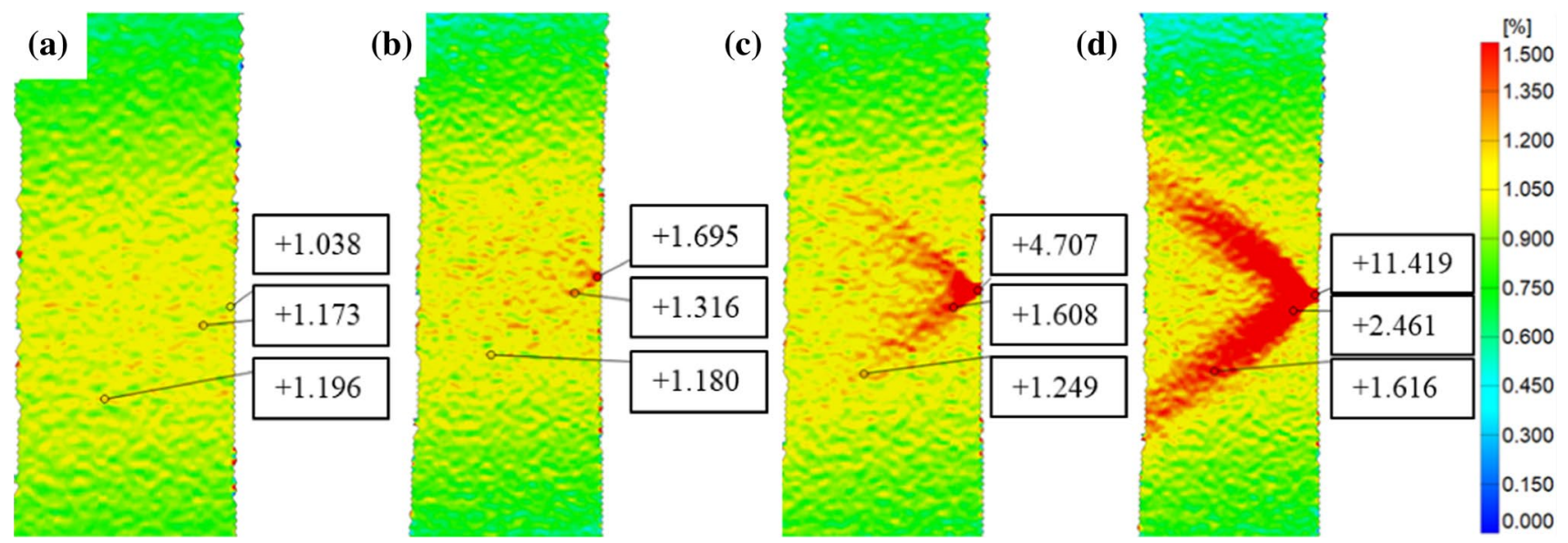

Fig.11 DIC measurements performed for the stress amplitude equal to $600 \mathrm{MPa}$ with unified scale after: 50 cycle (a); 130,000 cycles (b); 138,000 cycles $(\mathbf{c}) ; 144000$ cycles $(\mathbf{d})$

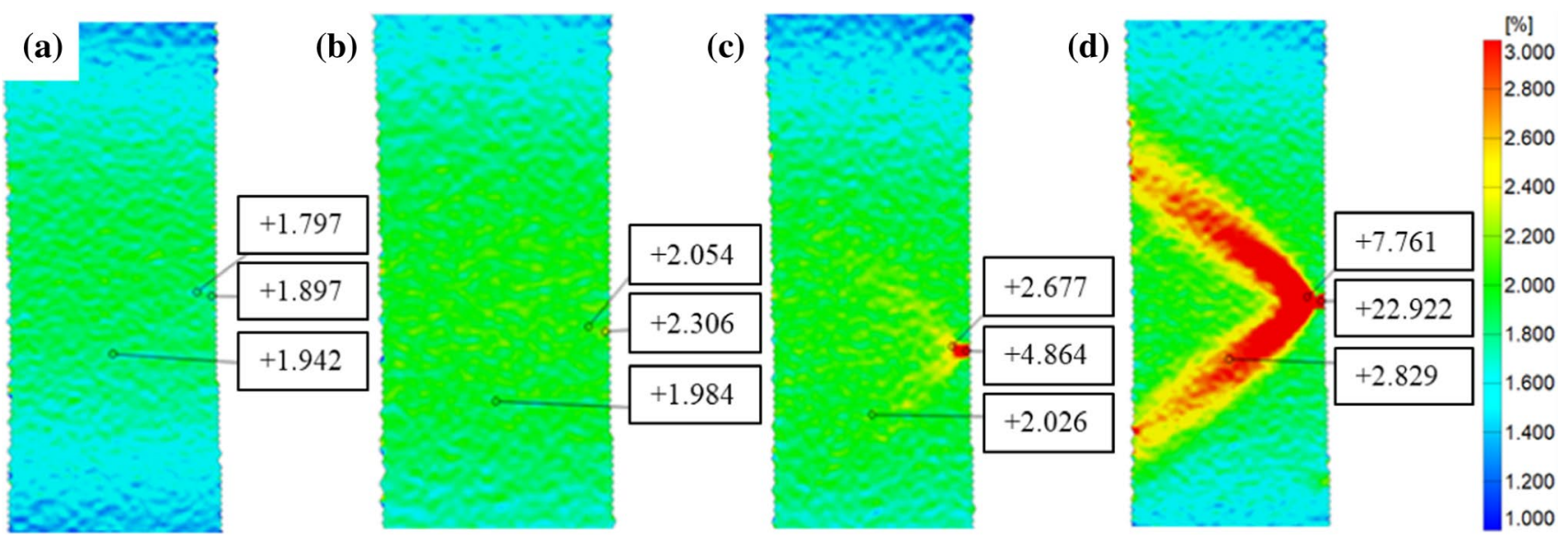

Fig.12 DIC measurements performed for the stress amplitude equal to $630 \mathrm{MPa}$ with unified scale after: 50 cycle (a); 50,000 cycles (b); 95,000 cycles $(\mathbf{c}) ; 110,000$ cycles $(\mathbf{d})$ 


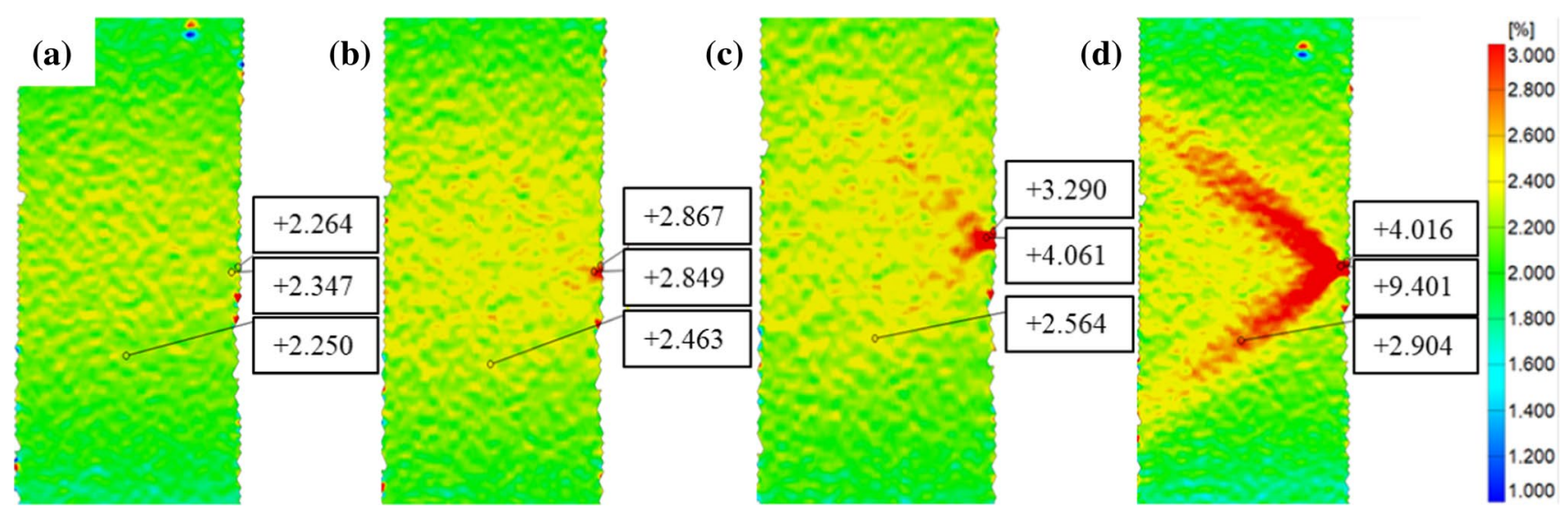

Fig.13 DIC measurements performed for the stress amplitude equal to $640 \mathrm{MPa}$ with the unified scale after: 30 cycle (a); 8750 cycles (b); 61,250 cycles $(\mathbf{c}) ; 92,489$ cycles $(\mathbf{d})$

Table 3 Advantages and disadvantages of ESPI and DIC [33-40]

\begin{tabular}{|c|c|c|}
\hline & Advantages & Disadvantages \\
\hline ESPI & $\begin{array}{l}\text { Noncontact measurement method with wavelength order accuracy } \\
\text { Provides a full-field measurement } \\
\text { Well suited for computer-aided measurements, as information is } \\
\text { acquired and evaluated digitally } \\
\text { Much higher sensitivity than that of holographic plates method } \\
\text { Almost a real-time operation. The correlation fringes can be } \\
\text { displayed on a monitor without the recourse to any form of pho- } \\
\text { tographic processing, or plate relocation } \\
\text { The resolution of the recording medium used need not be as high } \\
\text { as that required for the traditional holography } \\
\text { The sensitivity can be increased by } 20 \text { times with phase modula- } \\
\text { tion } \\
\text { High sensitivity to temperature fluctuations }\end{array}$ & $\begin{array}{l}\text { The measurement range of ESPI is small and limited by the } \\
\text { speckle correlation } \\
\text { For large objects, high-power lasers are required to increase the } \\
\text { average speckle pattern size } \\
\text { Equipment and installation cost of the setup is high } \\
\text { Difficult to use outside the laboratory } \\
\text { Require precise setup and low vibrational environments }\end{array}$ \\
\hline DIC & $\begin{array}{l}\text { Noncontact, full-field, and multipoint measurements } \\
\text { Simple experimental setup and specimen preparation } \\
\text { High efficiency } \\
\text { Great measurement accuracy and stability } \\
\text { High precision over the entire area } \\
\text { Wide measurement range (several millimetres to metres, high } \\
\text { temperature) } \\
\text { Accurate measurements of structures in typical outdoor environ- } \\
\text { ments } \\
\text { Full-field deformation analysis } \\
\text { A quick preparation of a random pattern of black dots on the white } \\
\text { background on the specimen surface by spraying paint }\end{array}$ & $\begin{array}{l}\text { Specimen surface has to be planar with a random pattern on the } \\
\text { surface } \\
\text { The dependence of the system on natural lighting conditions; the } \\
\text { need to apply artificial light when registering images with high } \\
\text { frequency } \\
\text { The need to use calibration tables appropriate to the size of the } \\
\text { tested sample area } \\
\text { Capacious storage media required to archive recorded images } \\
\text { Measurement errors strongly dependent on the size of measur- } \\
\text { ing area inaccuracies of averaging the results of calculations, } \\
\text { light condition changes during testing noises of digital camera, } \\
\text { angle between cameras and analysed surface, quality of the } \\
\text { lenses }\end{array}$ \\
\hline
\end{tabular}

to many new possibilities for surface displacement measurements. It was reported that the standard error of ESPI measurements was one order of magnitude smaller than for DIC. The authors emphasised that ESPI sensitivity scaled with a specimen size, while DIC sensitivity did not, and thus the simultaneous use of ESPI and DIC for surface deformation estimation was recommended to be performed at much smaller specimen scales. Halama et al. [41] performed strain and displacement contour comparison of ESPI and DIC under tension, shear and their combination.
The results captured were found as qualitatively comparable for all three loading types.

The ESPI and DIC measurements during fatigue tests have brought to date several aspects to be considered while discussing the effectiveness of both methods to fatigue damage development monitoring. It was noticed that, first, measurements performed by ESPI were always burdened with the error of high deformation occurrence caused by clamping the specimen in the grip of the hydraulic machine. During fatigue testing, such error was not observed, indicating that 
the clamping force should be carefully controlled during specimen exchange. On the other hand, both methods are very sensitive to a stress concentration on the specimen edge. The relatively large strain values found on the edge in comparison to strain values within the gauge area do not allow application of a uniform scale to present the results. This issue is much more important during ESPI measurements, as the strain distribution during damage development observed on the surface remained at the similar level up to the specimen fracture, and thus an identification of the potential fracture area is impossible. The stress concentration on the specimen edges was also observed during DIC measurements; however, this method enables to localise the area of potential crack at the early stage of fatigue development. The high sensitivity of the ESPI method does not allow to effectively monitor fatigue development even in the laboratory scale. The vibrations from the hydraulic testing machine together with the noise generated from the environment affect significantly the measurements, and as a consequence, greatly reduce the possible application of this method. The DIC technique, however, allows to detect the area with considerably higher strain accumulation even at the beginning of the test. Additionally, DIC could be successfully used to identify cracks on irregular surfaces. Qvale et al. [42] used full-field digital image correlation technique to identify crack initiation and early crack growth on corroded surfaces from offshore mooring chain.

The methodology of DIC fatigue damage development monitoring may be used together with the procedure presented in the authors' previous work [43], where the power exponent approximation of the fatigue damage measure $\phi$ and fatigue damage parameter $\mathrm{D}$ were successfully used to determine the fatigue life of P91 steel.

The fatigue damage parameter $\mathrm{D}$ describes the dynamics of deformation changes in subsequent cycles and is represented by the relationship:

$D=\frac{\varphi_{N}-\varphi_{\min }}{\varphi_{\max }-\varphi_{\min }}$

where $\varphi_{N}$-current value of the fatigue damage development measure in the cycle $N, \varphi_{\min }-$ minimum value of the fatigue damage development measure at the beginning of the cyclic loading, i.e. for the cycle $N=1, \varphi_{\max }$-maximum value of the fatigue damage development measure for the last cycle of the period of stable damage development $N_{f}$.

In this equation, damage measure was defined by:

$\varphi=\varepsilon_{w}+\varepsilon_{m}$

where $\varepsilon_{w}$-the inelastic strain amplitude is the damage indicator that characterises a width of the hysteresis loop at the total unloading, $\varepsilon_{m}$ - the mean inelastic strain responsible for a shift of the hysteresis loop under unloaded state.
The inelastic strain amplitude was measured at the total unloading of a material and was described in a single cycle by:

$\varepsilon_{w}=\frac{\varepsilon_{\max }^{F=0}-\varepsilon_{\min }^{F=0}}{2}$

The mean inelastic strain was also captured under unloaded state and was further defined by the relationship:

$\varepsilon_{m}=\frac{\varepsilon_{\min }^{F=0}+\varepsilon_{\max }^{F=0}}{2}$

The combination of these methodologies is presented in Figs. 14, 15, where an evolution of the fatigue damage parameter $\mathrm{D}$ as a function of the number of cycles to failure is shown for the stress amplitude of $500 \mathrm{MPa}$. A detailed description of the fatigue damage development expressed by an evolution of the fatigue damage parameter $\mathrm{D}$ associated with deformation mechanisms and microstructure evolution that occurred during cyclic loading was presented in [43]. Figure 15 presents an additional attempt to correlate the DIC measurements with evolution of the fatigue damage parameter $\mathrm{D}$, elaborated for the following number of cycles: $1 ; 100,000 ; 250,000$; and 301,251. The tempered martensite microstructure was found to be favourable for microcrack nucleation during fatigue. Such microstructure significantly accelerates the dynamics of the damage process in the first stage of deformation, and, moreover, the localised strain concentration could be easily found in the middle section of gauge length. Subsequent damage development in the next stages enabled an identification of the area of potential crack, and furthermore confirmed it in the final, third stage of damage, where the strain accumulation resulted from rapid increase of macrocracks and their subsequent propagation in the form of the dominant crack led to the material decohesion.

It was found that both of these methods, DIC and power exponent approximation of the $\mathrm{D}$ parameter, enable to reveal the dynamics of the degradation process in the first stage of fatigue up to 1000 cycles, and, thus, can be more effective than the conventional S-N curve approach. The correlation of these methods could be also effectively used for fatigue crack initiation detection along with complex physical models of fatigue crack initiation [44]. It should be highlighted that the experimental findings presented in [44] were also in agreement with those of the authors' previous studies [43], in which the initiation of fatigue cracks was also associated with intrusions within the materials. Additionally, such methodology could be successfully used as an alternative approach to the well-known non-destructive testing methods for measuring crack growth including optical, compliance, ultrasonic, acoustic emission [45], eddy current, alternating current field, and potential difference (PD) methods [46] or 
Fig. 14 Hysteresis loops for the stress amplitude of $500 \mathrm{MPa}$ correlated with the DIC measurements performed after 1,100,000, 250,000 and 301,251 cycles

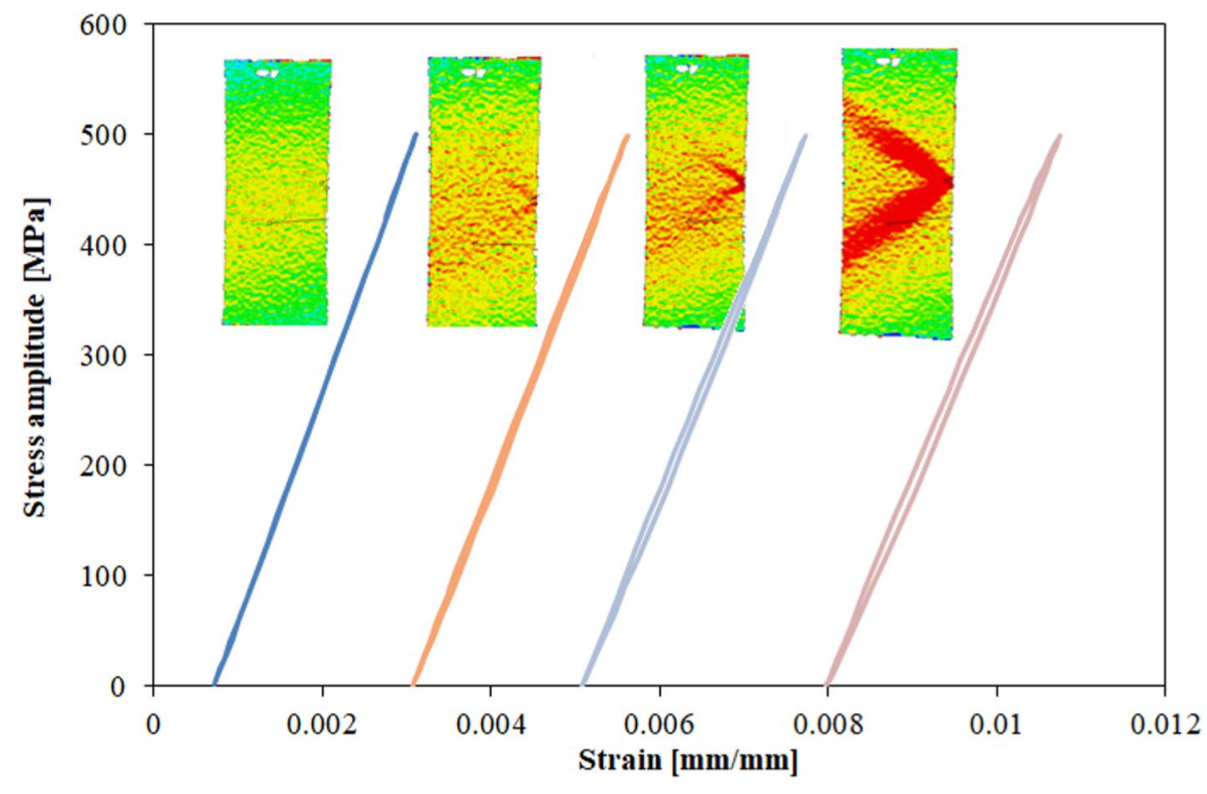

Fig. 15 Development of the fatigue damage for the stress amplitude of $500 \mathrm{MPa}$ expressed by evolution of the fatigue damage parameter $\mathrm{D}$ correlated with the DIC measurements performed after 1 , $100,000,250,000$ and 301,251 cycles

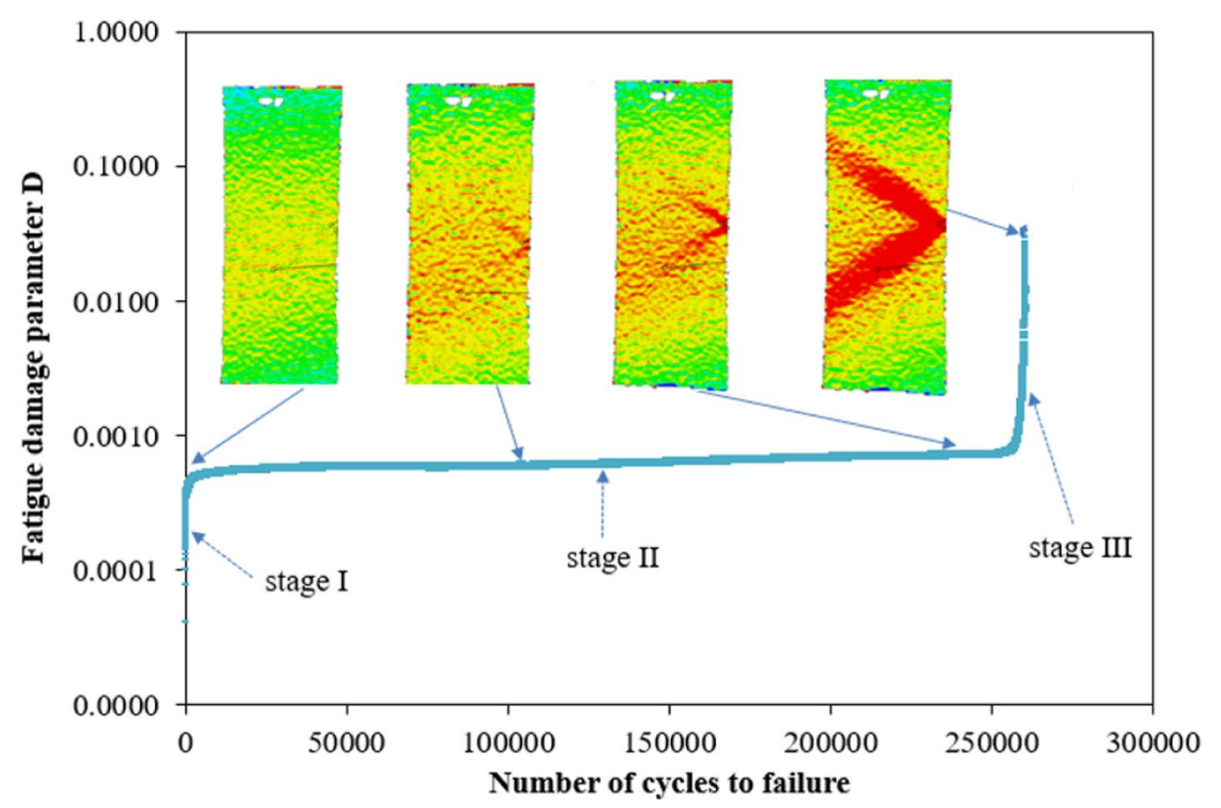

even probabilistic methods for fatigue crack initiation prediction [47].

\section{Conclusions}

In this paper, steel specimens subjected to fatigue loadings in the range of stress amplitude from \pm 400 to $\pm 640 \mathrm{MPa}$ were monitored by using two different optical measurement techniques (ESPI and DIC). The techniques were assessed in terms of their effectiveness to fatigue damage development monitoring in $\mathrm{P} 91$ power engineering steel. It was found that DIC enables to monitor the fatigue behaviour and accurately indicate the area of potential failure within the early stage of fatigue damage development. Contrary to this, the application of thw ESPI method was not so successful. It also enabled to indicate the location of potential damage area, however, significantly later than DIC. The main limitation of ESPI technique usage results from its high sensitivity which procures many difficulties during working with the servo-controlled hydraulic testing machines. Such machines generate high-frequency vibrations during experiments due to oil flow supplying the machine loading systems. The vibrations disturb significantly the work of ESPI cameras and narrows greatly its measuring capabilities. 
Acknowledgements The authors would like to express their gratitude to the technical staff-Mr. M. Wyszkowski, Miss. I. Barwinska and Mr. A. Chojnacki for their kind help during experimental part of this work. This work has been partially supported by the National Science Centre through the Grant No 2019/35/B/ST8/03151.

Author contributions Conceptualisation-ZK, MK; data curation$\mathrm{AB}$; formal analysis- $\mathrm{ZK}, \mathrm{MK}$; investigation- $\mathrm{AB}, \mathrm{MK}$; methodology-DK, ZK; project administration-ZK; supervision-ZK; validation-ZK, MK; visualisation-DK, MK; roles/writing-original draft-MK; writing — review and editing-ZK.

Open Access This article is licensed under a Creative Commons Attribution 4.0 International License, which permits use, sharing, adaptation, distribution and reproduction in any medium or format, as long as you give appropriate credit to the original author(s) and the source, provide a link to the Creative Commons licence, and indicate if changes were made. The images or other third party material in this article are included in the article's Creative Commons licence, unless indicated otherwise in a credit line to the material. If material is not included in the article's Creative Commons licence and your intended use is not permitted by statutory regulation or exceeds the permitted use, you will need to obtain permission directly from the copyright holder. To view a copy of this licence, visit http://creativecommons.org/licenses/by/4.0/.

\section{References}

1. Chu TC, Ranson WF, Sutton MA, Peters WH. Application of digital-image-correlation techniques to experimental mechanics. Exp Mech. 1985;25:232-44. https://doi.org/10.1007/BF023 25092.

2. Lord JD. Digital image correlation (dic). In: Eaton-Evans J, DulieBarton JM, Burguete RL, editors. Modern stress and strain analysis. A state of the art guideto measurement techniques. British Society for Strain Measurement; 2009. p. 14-5.

3. Forster J, Theobald A, Engel S, Pasmann R. Using optical measuring system for identification of material parameters for finite element analysis. In: 11. LS-DYNA, DYNAmore GmbH, Ulm, 2012. p. 1-9.

4. Durif E, Réthoré J, Combescure A, Fregonese M, Chaudet P. Controllingstress intensity factors during a fatigue crack propagation using digital imagecorrelation and a load shedding procedure. Exp Mech. 2012;52:1021-31. https://doi.org/10.1007/ s11340-011-9552-6.

5. Andersson M. The influence of notches on fatigue of heat treated sintered steel. In: International Powder Metallurgy Congress and Exhibition (2013) Euro PM2013 in Gothenburg on September 17, 2013.

6. Han Y, Kim DW, Kwon HJ. Application of digital image crosscorrelation and smoothing function to the diagnosis of breast cancer. J Mech Behav Biomed Mater. 2012;14:7-18. https://doi.org/ 10.1016/j.jmbbm.2012.05.007.

7. Hokka M, Mirow N, Nagel H, Irqsusi M, Vogt S, Kuokkala VT. In-vivo deformation measurements of the human heart by 3D digital image correlation. J Biomech. 2015;48:2217-20. https://doi. org/10.1016/j.jbiomech.2015.03.015.

8. Juszczyk MM, Cristofolini L, Viceconti M. The human proximal femur behaves linearly elastic up to failure under physiological loading conditions. J Biomech. 2011;44:2259-66. https://doi.org/ 10.1016/j.jbiomech.2011.05.038.

9. Zani L, Erani P, Grassi L, Taddei F, Cristofolini L. Strain distribution in the proximal Human femur during in vitro simulated sideways fall. J Biomech. 2015;48:2130-43. https://doi.org/10. 1016/j.jbiomech.2015.02.022.

10. Yoon S, Jung H-J, Knowles JC, Lee H-H. Digital image correlation in dental materials and related research: a review. Dental Mater. 2021;37:758-71. https://doi.org/10.1016/j.dental.2021.02. 024.

11. Berke R, Lambros J. Ultraviolet digital image correlation (UV-DIC) for high temperature applications. Rev Sci Instrum. 2014;85:4.

12. Niezrecki C, Avitabile P, Warren C, Pingle P, Helfrick M. A review of digital image correlation applied to structura dynamics AIP Conference proceedings. Am Inst Phys. 2010;1253:219-32.

13. Lunt AJG, Korsunsky AM. A review of micro-scale focused ion beam milling and digital image correlation analysis for residual stress evaluation and error estimation. Surf and Coati Tech. 2015;283:373-88. https://doi.org/10.1016/j.surfcoat.2015.10.049.

14. Cunha FG, Santos TG, Xavier J. In situ monitoring of additive manufacturing using digital image correlation: a review. Materials. 2021;14:1511. https://doi.org/10.3390/ma14061511.

15. Pagliarulo V, Ferraro P. New applications of electronic speckle pattern interferometry in novel materials and structures. In: Proceedings SPIE 11059, Multimodal Sensing: Technologies and Applications, 1105910 (2019); https://doi.org/10.1117/12.25279 97.

16. Ramault C, Makris A, Van Hemelrijck D, Lamkanfi E, Van Paepegem W. Comparison of different techniques for strain monitoring of a biaxially loaded cruciform specimen. Strain. 2011;47:210-7. https://doi.org/10.1111/j.1475-1305.2010. 00760.x.

17 Rajic N, Street N, Brooks C, Galea S. Full field stress measurement for insitu structural health monitoring of airframe components, 7th European Workshop on Structural Health Monitoring. Nantes: La Cité; 2014.

18. Siebert T, Schubach H-R, and Splitthof K. Recent developments and applications for optical full field strain measurement using ESPI and DIC. In: Proceedings SPIE 7997, Fourth International Seminar on Modern Cutting and Measurement Engineering, 79972B (26 May 2011); https://doi.org/10.1117/12.891864.

19. Bingleman L, Schajer GS. ESPI Measurements in the Presence of Large Lateral Displacements. In: Proulx T, editor. Application of Imaging Techniques to Mechanics of Materials and Structure, Conference Proceedings of the Society for Experimental Mechanics Series, vol. 4. New York: Springer; 2013.

20. Wang R, Kido M. Using ESPI system to measure high temperature fatigue deformation of ceramics thermally sprayed SUS304 steel. J Mater Sci. 2004;39:1389-95. https://doi.org/10.1023/B:JMSC. 0000013902.30089.1f.

21. Kopeć M, Grzywna P, Kukla D, Kowalewski ZL. Evaluation of the fatigue damage development using ESPI method. Inżynieria Materiałowa. 2016;212:201-5. https://doi.org/10.15199/28. 2016.4.9.

22. Ustrzycka A, Mróz Z, Kowalewski ZL, Kucharski S. Analysis of fatigue crack initiation in cyclic microplasticity regime. Int J Fat. 2020;131:105342-1-105415. https://doi.org/10.1016/j.ijfatigue. 2019.105342.

23. Liu W, Huang J, Liu J, Wu X, Zhang K, Huang A. Experimental and crystal plasticity modelling study on the crack initiation in micro-texture regions of Ti-6Al-4V during high cycle fatigue tests. Int J Fat. 2021;148: 106203. https://doi.org/10.1016/j.ijfat igue.2021.106203.

24. Hunsche A, Neumann P. Quantitative measurement of persistent slip band profiles and crack initiation. Acta Metall. 1986;34:20717. https://doi.org/10.1016/0001-6160(86)90192-6.

25 Song H, Liu C, Zhang H, Leen SB. A DIC-based study on fatigue damage evolution in pre-corroded aluminum alloy 2024-T4. Materials. 2018;11:2243. https://doi.org/10.3390/ma11112243. 
26. Patriarca L, Foletti S, Beretta S. LCF and crack growth: recent results obtained by DIC. MATEC Web Conf. 2018;165:0100. https://doi.org/10.1051/matecconf/201816501001.

27. Gonabadi H, Oila A, Yadav A. Fatigue damage analysis of GFRP composites using digital image correlation. J Ocean Eng Mar Energy. 2021;7:25-40. https://doi.org/10.1007/ s40722-020-00184-6.

28. Foti F, Pannier Y, Mellier D, Gigliotti M. Damage characterization during high temperature fatigue of off-axis woven organic matrix composites for aircraft applications IOP Conf Series. Mater Sci Eng. 2018;406:012055. https://doi.org/10.1088/1757-899X/406/1/ 012055.

29. Yuan F, Cheng L, Shao X, Dong Z, Zhang L, Wu G, He X. Fullfield measurement and fracture and fatigue characterizations of asphalt concrete based on the SCB test and stereo-DIC. Eng Fract Mech. 2020;235: 107127. https://doi.org/10.1016/j.engfracmech. 2020.107127.

30. Polish Standard PN10216-2 Steel tubes for pressure purposestechnical delivery conditions-Part 2: non-alloy and alloy steel tubes with specified elevated temperature properties. 2004. https:// sklep.pkn.pl/pn-en-10216-2-2014-02p.html

31. Ni M, Wang J, Liu J, et al. Microstructure and mechanical properties of P91 steel during heat treatment: the effect of the cooling speed during the normalization stage. J Mater Eng Perform. 2021;30:2329-40. https://doi.org/10.1007/s11665-021-05534-5.

32 Pandey C, Mahapatra MM, Kumar P, Saini N. Some studies on P91 steel and their weldments. J Alloys Compd. 2018;743:33264. https://doi.org/10.1016/j.jallcom.2018.01.120.

33. Marakani A, Mandanala N. Electronic speckle pattern interferrometry. EML 5111L experimental stress analysis. Springer; 2016.

34. Bavigadda V. A new versatile electronic speckle pattern interferometer for vibration measurements. Doctoral Thesis. Technological University Dublin. 2013. https://doi.org/10.21427/D7DW2N

35 Tomasini EP, Revel GM, Castellini P. Laser based measurements. In: Braun S, editor. Encyclopedia of vibration. USA: Elsevier; 2001. p. 699-710.

36. Hedayat A, Ashur S. Digital image correlation and its application in an undergraduate civil engineering materials laboratory. US: Fort Wayne; 2015.

37. Zhou J-W, Liu D-H, Shao L-Y, Wang Z-L. Application of digital image correlation to measurement of packaging material mechanical properties. Math Prob Eng. 2013;2013:1-8. https://doi.org/10. $1155 / 2013 / 204875$.
38. McCormick N, Lord J. Digital image correlation. Mat Tod. 2010;13:52-4. https://doi.org/10.1016/S1369-7021(10)70235-2.

39. Górszczyk J, Malicki K, Zych T. Application of Digital Image Correlation (DIC) method for road material testing. Materials. 2019;12:2349. https://doi.org/10.3390/ma12152349.

40. Krawczyk $€$, Gołdyn M, Urban T. Digital image correlation systems in the experimental investigations: capabilities and limitations. Arch Civil Eng. 2019;65:171-80. https://doi.org/10.2478/ ace-2019-0012.

41. Halama R, Hornacek L, Smiraus J. Combination of the ESPI and DIC techniques opens many new possibilities for surface displacement measurements. In: 55th International Conference on Experimental Stress Analysis (EAN 2017) 30 May-1 June 2017, Novy Smokovec, Slovakia.

42. Qvale P, Zarandi EP, Ås SK, Skallerud BH. Digital image correlation for continuous mapping of fatigue crack initiation sites on corroded surface from offshore mooring chain. Int J Fat. 2021;151: 106350. https://doi.org/10.1016/j.ijfatigue.2021. 106350.

43. Kopec M, Kukla D, Brodecki A, Kowalewski ZL. Effect of high temperature exposure on the fatigue damage development of $\mathrm{X} 10 \mathrm{CrMoVNb} 9-1$ steel for power plant pipes. Int J Pres Ves. 2021;189:104282-1-104316. https://doi.org/10.1016/j.ijpvp. 2020.104282.

44. Polák J, Man J. Experimental evidence and physical models of fatigue crack initiation. Int J Fat. 2016;91(2):294-303. https://doi. org/10.1016/j.ijfatigue.2016.02.021.

45. Karimian SF, Modarres M, Bruck HA. A new method for detecting fatigue crack initiation in aluminum alloy using acoustic emission waveform information entropy. Eng Fract Mech. 2020;223: 106771. https://doi.org/10.1016/j.engfracmech.2019.106771.

46. Si Y, Rouse JP, Hyde CJ. Potential difference methods for measuring crack growth: a review. Int J Fat. 2020;136: 105624. https:// doi.org/10.1016/j.ijfatigue.2020.105624.

47. Kulkarni SS, Sun L, Moran B, et al. A probabilistic method to predict fatigue crack initiation. Int J Fract. 2006;137:9-17. https:// doi.org/10.1007/s10704-005-3074-0.

Publisher's Note Springer Nature remains neutral with regard to jurisdictional claims in published maps and institutional affiliations. 